\title{
Fuentes para el estudio de la represión franquista en el Archivo Histórico Nacional, sección «Guerra Civil»
}

\author{
Antonio González Quintana
}

\section{INTRODUCCIÓN}

La denominación con la que fue incorporado al Archivo Histórico Nacional, por orden del Ministerio de Cultura de 7 de mayo de 1979 ', el conjunto de documentos producidos o acumulados en el ejercicio de sus funciones por los Servicios Documentales de Presidencia del Gobierno es, al menos, equívoca.

En efecto, la Sección "Guerra Civil», nombre que sirvió para bautizar esta incorporación de documentos al Archivo, además de no hacer justicia, - como trataremos de aclarar en esta contribución-, al contenido informativo de los mismos, creó una nueva agrupación temática, temático-cronológica en este caso, que, a la larga, ha motivado que se haya ido desdibujando el carácter marcadamente orgánico de estos fondos documentales.

Si algo caracteriza la documentación de archivo frente a la custodiada en otras instituciones como bibliotecas o centros de documentación, es, precisamente, ese carácter orgánico y funcional que contextualiza los documentos y les da su justo valor en cada momento. Sin excepción, y esta es una de las ideas centrales que pretendo enfatizar en esta ponencia, todos esos documentos incorporados al Archivo Histórico Nacional en 1979, jugaron un papel, o mejor dicho, cumplieron una función represiva de mayor o menor magnitud.

Esta disposición adscribe al Archivo Histórico Nacional los fondos documentales de la extinguida Sección de Servicios Documentales, formando en el mismo una División independiente, «a fin de integrar los referidos fondos documentales en el sistema general de archivos dependientes de este Ministerio (Cultura), y teniendo en cuenta la naturaleza de los mismos". («B.O.E.", $n^{0} 184$, de 21 de junio de 1979). 
independientemente de sus productores originarios y de la primaria finalidad de los mismos, desde 1937 hasta $1977^{2}$ en que quedaron bajo la responsabilidad del recién creado Ministerio de Cultura, tales documentos se deben entender al servicio de los organismos y cuerpos represivos del "nuevo estado". En este contexto es en que debemos acercarnos a ellos, al menos en primera instancia.

En 1977, en el momento del inicio de la etapa democrática que vivimos, todos los materiales de que estamos hablando dependian de los Servicios Documentales de Presidencia del Gobierno, organismo que, de un modo u otro, habia ido asumiendo las competencias informativas sobre antecedentes político-sociales o masónicos y, asimismo, había recogido en su seno, por decreto de 21 de enero de $1971^{3}$, el archivo de una de las instituciones represivas al servicio de la cual habian venido trabajando estos servicios y sus organismos precedentes de forma más significativa: el Tribunal Especial para la Represión de la Masonería y el Comunismo, desaparecido en 1963.

En el citado momento de la integración, la Sección de Servicios Documentales de Presidencia del Gobierno, además de contar con los documentos producidos o acumulados por ella misma y sus organismos precedentes, a saber, Oficina de Investigación y Propaganda Anticomunista (OIPA), Delegación de Servicios Especiales, Delegación del Estado para la Recuperación de Documentos y delegaciones territoriales de ésta última, era consignataria del fondo documental producido por el Tribunal Especial para la Represión de la Masonería y el Comunismo.

Todos estos fondos documentales, con tener una personalidad propia definida y merecer un tratamiento archivístico independizado, están, no cabe duda, intimamente relacionados. Tienen dos denominadores comunes: 1) servir a la causa de la represión y 2) alimentarse de una fuente informativa común: los documentos incautados a las instituciones consideradas enemigas del nuevo régimen. En todo caso, por tanto, parecería más lógico que a esa división independiente a establecer en el Archivo Histórico Nacional se la hubiese denominado de forma más acorde a esos

\footnotetext{
2 Por el Real Decreto 2.761/1977, por el que se reorganiza la Presidencia del Gobierno, de. saparece, entre otros organismos, la Sección de Servicios Documentales, "cuyos fondos de documentación se adscriben al Ministerio de Cultura" ("B.O.E.", no 267, de 8 de noviembre de 1977).

3 El "B.O.E." de 27 de enero de 1971 publicaba este decreto, por el que se suprime la Comisión Liquidadora det Tribunal Especial para la Represión de la Masonería y el Comunismo, disponiendo en su art. $3^{\circ}$ la entrega del Archivo del Tribunal a los Servicios Documentales de Presidencia del Gobierno.
} 
parámetros de unidad de estos fondos, por ejemplo con el apelativo de "Sección Represión de la Masonería y el Comunismo" o algo similar. Parece, no obstante, que en el momento político de aquellas actuaciones la denominación de "Sección Guerra Civil» podía actuar como eufemismo que facilitara la vía de integración de este patrimonio documental en el sistema estatal de archivos dependientes del Ministerio de Cultura, por cuanto la guerra civil podía ser un ámbito cronológico y temático que no provocara recelo excesivo; no sucedía lo mismo, obviamente, con el tema de la represión del régimen recientemente abandonado.

\section{LA RECUPERACIÓN DE DOCUMENTOS}

\section{a) Los organismos pioneros}

La ubicación en Salamanca de los servicios informativos enunciados se situó, desde el inicio de los mismos, en el marco de la provisionalidad. La creación de las dos primeras instituciones objeto de nuestro estudio (cronológicamente hablando): la Oficina de Investigación y Propaganda Anticomunista y la Delegación de Asuntos Especiales, en el seno del Cuartel General de Franco, impulsadas desde la Secretaría Particular de éste, explicarian la circunstancialidad de tal acómodo. $Y$ si bien durante la circunstancialidad de tal acómodo. Y si bien durante la guerra había que fijar un lugar geográficamente estable al que ir haciendo los envíos de documentos, sin hacer correr a estos servicios un destino paralelo en la itinerancia al del cuartel general, inmediatamente de finalizada la guerra, se busca un lugar definitivo para los "archivos", siempre en las proximidades de Madrid. Lo cierto es que aquella provisionalidad ha llegado a nuestros días y lo fundamental a destacar de ella es que obligó a un trasiego de coches y transportes en general, casi continuo, entre Madrid y Salamanca, sobre todo entre los años 1939-1963.

A pesar, no obstante, de que el fin utilitario básico de estos organismos fue la represión política, no sería asumido este cometido como objetivo central hasta finales de 1937. Un cierto mesianismo redentor, con componentes historicistas, va a ser, más bien, el que esté presente entre las metas que fijan los primeros organizadores de los servicios. Se piensa en la necesidad de mostrar al mundo, de acuerdo con todas las instituciones internacionales en plano ideológico similar (Antikomintern...), las maldades del comunismo, de la masoneria, del judaismo. Además, se juzga imprescindible el conocimiento de la propaganda enemiga para realizar eficazmente la contrapropaganda propia. 
Así, desde la Secretaria General de S.E. el Jefe del Estado, Nicolás Franco dictaba una orden, con fecha 20 de abril de 1937, por la que se creaba la OIPA (Oficina de Investigación y Propaganda Anticomunista), dependiente de la citada Secretaría General y con la misión de

«... recoger, analizar y catalogar todo el material de propaganda de todas clases que el comunismo y sus organizaciones adlateres hayan utilizado para sus campañas en nuestra patria, con el fin de organizar la correspondiente contrapropaganda, tanto en España como en el extranjero, en colaboración con las instituciones anticomunistas existentes, tales como el Antikomintern de Berlín, el Instituto de Investigación Científica del Comunismo en Varsovia, la institución antimarxista "Maitre Aubert" en Ginebra, la "National Herstel" en Holanda, etc.».

Por otra parte la comentada orden va a ir concretando cuáles son esas organizaciones adláteres anteriormente citadas, al decir que se tratará de recoger la mayor cantidad posible de pruebas de las actividades marxistas en España señalando:

«... y en particular, la documentación de las sociedades masónicas, Liga de Derechos del Hombre, Amigos de Rusia, Socorro Rojo Internacional, Cine Clubs (material cinematográfico), Ligas Anti-Fascistas, Ateneos Libertarios, Instituciones Naturistas, Ligas contra la Guerra y el Imperialismo, Asociaciones Pacíficas, Federación de los Trabajadores de la Enseñanza, etc... ${ }^{4}$.

Es curioso observar, en estas referencias concretas, la ausencia de toda alusión al propio Partido Comunista o a cualquier otro partido político del Frente Popular, así como a las organizaciones sindicales como la UGT o la CNT, excepción hecha de la mención a la Federación de Trabajadores de la Enseñanza de la central socialista. Parece claro que las auténticas "bestias negras" de la propaganda enemiga las constituyen, desde el punto de vista de los rebeldes, las entidades culturales, los movimientos racionalistas y, sobre todo la Masonería, auténtico banderín de enganche para la propaganda franquista.

Esa obsesión por la Masonería, ampliamente documentada ya, llevaría a la constitución, igualmente desde el Cuartel General de Franco, un mes aproximadamente después de creada la OIPA, de un organismo especialmente dedicado a la contrapropaganda masónica pero con una mucho más clara, esta vez, vocación represiva: la Delegación de Asuntos

4 AHN, SGC. Servicios Documentales de Presidencia del Gobierno, Secretaría General (a partir de ahora "AHN, SGC: DSD/Sec."). Exptes. de asuntos y correspondencia, leg. 23. 
Especiales ${ }^{5}$. La intervención de Franco directa sobre el tema queda claramente reflejada en la memoria que, a los quince meses del funcionamiento del organismo, le presente el delegado, D. Marcelino de Ulibarri y Eguilaz, carlista, hombre fervorosamente religioso y de empeño denodado en la cruzada particular que para él supondrán los servicios que, a partir de este momento de mayo de 1937, en que es nombrado delegado de estos "Servicios Especiales", van a ir recayendo sobre su directa responsabilidad y de los cuáles, si no el único, va a ser, sin duda alguna, el más destacado protagonista. En este texto, básico para comprender la idiosincrasia de esta curiosa aplicación de la apropiación de documentos del enemigo como fuente para la represión del mismo, al exponer el balance de su actuación, Ulibarri parte de las ordenes verbales recibidas de S.E.:

"(que) procurase recuperar cuanta documentación relacionada con las sectas y sus actividades en España, estuviese en poder de particulares, autoridades y organismos oficiales, guardándola cuidadosamente en lugar alejado de todo peligro, y en el que pudiera ordenarse y clasificarse para llegar a constituir un Archivo que nos permitiera conocer, desenmascarar y sancionar a los enemigos de la patria" ${ }^{6}$.

Mucho se ha especulado con los motivos reales de la inquina de Franco hacia la orden del triángulo, pero no sería descabellado, atribuirla, esencialmente al miedo a la encubración a los resortes del poder emergente de miembros de la masonería y, sobre todo, a que éstos pudieran contar con el soporte de una organización discreta en la que la conspiración pudiera estar presente, sobre todo tratándose de militares, tradicionalmente muy activos, sobre todo en períodos anteriores en la Masonería Española. De ahí la insistencia en la concentración de los documentos masónicos y en la seguridad de los mismos, así como la exhaustividad en la recogida de los mismos, que no se dio, por cierto, en el caso de la documentación de tipo político o social. Por otra parte, como veremos a continuación, el control de estos últimos documentos pasaría pronto, con la organización del primer gobierno del nuevo estado, a depender del Ministerio del Interior, mientras que la documentación masónica, estaría durante muchos años ligada directamente al general Franco, primero a su Secretaría particular y luego a la Presidencia del Gobierno. Incluso cuando dejó de ejercer esta última directamente se puede valorar que ese

5 La Delegación de Asuntos Especiales se constituyó, por Orden de la Secretaría Particular de S.E. el Jefe del Estado, el dia 29 de mayo de 1937.

6 AHN, SGC: DSD/Sec. Expedientes de asuntos y correspondencia, leg. 5, expte. 97. 
control cierto no desaparecería, ya que D. Luis Carrero Blanco tuvo, como el propio Jefe del Estado, una estrechísima vinculación con los servicios documentales salmantinos, demostrando siempre un gran interés por los mismos. En la citada memoria de D. Marcelino de Ulibarri se hace mención a lo difícil que, en algunos casos, resulto ser hacerse con determinada documentación masónica en manos de ciertas autoridades militares, vinculadas a la justicia militar, y de determinadas instituciones falangistas.

\section{b) La Delegación del Estado para la Recuperación de Documentos}

Si bien la Delegación de Asuntos Especiales se aplicó con prontitud a la tarea de identificar masones y preparar con ello un centro de información para la represión de éstos, la OIPA centró su labor en el acopio de material impreso editado, menos rico, informativamente hablando, en la aportación de antecedentes sobre personas que el material de archivo.

El cambio de orientación en el objetivo en la incautación de documentos a las instituciones político-sociales, como se denominaba al amplísimo espectro de organizaciones opuestas a la sublevación, vendría con la puesta en marcha, otra vez por iniciativa del Cuartel General de Franco de un servicio denominado «Recuperación de Documentos». Este servicio, comenzó su actuación con motivo de la toma de Bilbao, pudiendo considerar ésta una experiencia piloto para posteriores actuaciones. Al frente de esta incautación estuvo D. Manuel Maestro, uno de los tres componentes de la comisión que se establecía, —en la ya citada orden de abril 1937para la puesta en marcha de la OIPA. Nace pues el servicio de Recuperación de Documentos a la sombra y al amparo de aquella, pero, pasados unos meses y ante la envergadura que el trabajo fue adquiriendo, acabó absorbiendo en su seno a la primera oficina.

En febrero de 1938, requerido por don Ramón Serrano Suñer, flamante ministro del Interior, D. Marcelino de Ulibarri pasa a hacerse cargo de la OIPA, optándose claramente desde ese momento por su fusión con los servicios de Recuperación ? ${ }^{7}$. Tras la actuación pionera en Bilbao, D. Marcelino de Ulibarri escribe a Franco, con fecha 4 de agosto de 1937, planteándole la necesidad de asentar sobre bases sólidas el recién

Véanse al respecto: "Presupuesto y organización de Recuperación de Documentos y OIPA (11 de febrero de 1938)" y "carta de D. Marcelino de Ulibarri a D. Ramón Serrano Suñer, 16 de febrero de 1938). En: AHN, SGC: DSD/Sec. Expedientes de asuntos y correspondencia, leg. 23. 
estrenado servicio, marcando las pautas por las que debía regirse y las relaciones que había de mantener, con el resto de organismos oficiales de la España franquista y, en particular, con la Auditoría del Ejército de Ocupación. Como consecuencia de sus propuestas y, "con la intervención de los señores D. Ramón Serrano Suñer y del Teniente Coronel Martínez Maza" ${ }^{8}$ se nombró jefe de estos servicios de Recuperación de Documentos a D. Laureano Armas, aceptándose la propuesta de Ulibarri de D. Manuel Martín Sastre, teniente auditor, como jefe de la oficina. Este último actuaría como coordinador de un equipo de hombres destacado en vanguardia con la misión de ocupar, inmediatamente antes que el grueso de las tropas, los locales de las instituciones republicanas así como de las organizaciones político-sociales y proceder a la consabida incautación de material documental.

Pero a diferencia de lo ocurrido con la OIPA, ya son los documentos de archivo pieza singularmente codiciada, con el fin de preparar las pruebas de convicción necesarias para la actuación de la justicia militar. En la mencionada exposición a Franco de 4 de agosto de $1937^{9}$, se sientan ya las bases funcionales y doctrinales de Recuperación de Documentos. En cuanto a la función del organismo se plantea que ya el nombre la define de manera clara y exacta:

«... recuperará para España, para el Estado naciente, los documentos que nuestros enemigos van dejando en su huida...",

asimismo se hace hincapié en la trascendencia de la labor, diferenciando con una clara línea de ruptura el comportamiento anterior para con los documentos del enemigo:

«... La creación de la Oficina de Recuperación de Documentos marca una etapa y señala una regulación en la forma de recoger y ordenar los que se hallen. De la simple aprehensión por el primer ocupante, que bien intencionado, pero que desconocedor del mecanismo del nuevo Estado, no puede poner a disposición el que más lo necesite o más partido pueda sacar, pasamos con la creación de esta oficina a una regulación que llena necesidades y cumple un importante cometido...".

8 Nota de D. Marcelino de Ulibarri sobre el "Servicio de Recuperación de Documentos" (24 de enero de 1938). En: AHN, SGC: DSD/Sec. Expedientes de Asuntos y correspondencia, leg. 23.

${ }^{9}$ «Recuperación de Documentos. $1^{\circ}$ Función. $2^{\circ}$ Modo de desarrollarla. $3^{\circ}$ Su relación con centros oficiales. $4^{\circ}$ Su relación con la Auditoria del Ejèrcito de Ocupación". En: AHN, SGC: DSD/Sec. Expedientes de asuntos y correspondencia, leg. 23. 
Dos serian las condiciones básicas para poder desarrollar esta tarea, ambas citadas en el texto: "exclusividad de actuación" y "continuidad en la función».

La continuidad se entendió como la fórmula que debia acompañar a la exclusividad, toda vez que cualquier dejación o relajación, siquiera momentánea podía poner en peligro la deseada exclusividad. Para garantizarla era necesaria una buena dotación de personal, estable y selecta. Se juzgaba como absolutamente necesario
«... contar en el plazo de tiempo más corto con un personal numeroso y competente, al que se le hayan dado las normas esenciales para la recogida de documentos, y que pueda actuar llegado el momento con un poco de cri- terio propio y suficiente sentido común..." ${ }^{10}$.

Si no la carencia, ya que en algún momento la cifra de personal adscrito al servicio de Recuperación de Documentos llegó a las doscientas personas entre las múltiples dependencias con que llegó a contar, dispersas por múltiples localidades de la geografía española, la provisionalidad de la plantilla sería una constante del servicio. La recluta del personal procedia, por falta de dotación propia, justificada por el carácter coyuntural que al centro se daba en las altas esferas, de

“... elementos voluntarios o militarizados, más algunos oficiales jurídicos o de complemento cedidos por sus cuerpos respectivos..." $"$.

Pero el caballo de batalla fundamental sería el de la exclusividad en la función. Fueron múltiples y muy variados los organismos represivos constituidos en el nuevo estado, e igualmente numerosas las entidades que en el momento de la derrota ponían en marcha, al margen de los organismos oficiales tanto la represión como la requisa, llegándose a un extremo de alta preocupación incluso en el centro neurálgico de la Falange. Pero si bien la práctica represiva en cuanto a las ejecuciones incontroladas no iba a variar sustancialmente prácticamente hasta el final de la guerra, la cuestión de la apropiación de los documentos del enemigo si iba a tener una clara tendencia a la concentración. Sin embargo, esa política encontraría determinados obstáculos en su camino. Las nuevas autoridades locales,

10 "Recuperación de documentos en la actualidad" (informe sin fecha y sin firma) (diciembre de 1937). En: AHN, SGC: DSD/Sec. Expedientes de Asuntos y correspondencia, leg. 23.

1 Carta del Delegado del Estado para la Recuperación de Documentos al Subsecretario del Ministerio de Gobernación (4 de octubre de 1941). En: AHN, SGC: DSD/Sec. Expedientes de asuntos y correspondencia, leg. 23. 
sobre todo del partido recientemente unificado (FET), y el ejército entraron en competencia clara con Recuperación de Documentos. De esta competencia encontramos testimonios puntuales abundantes en las reclamaciones de documentación a múltiples organismos. $Y$ en algún caso tuvieron costosa resolución.

Podríamos achacar a esa confrontación el hecho de que los resultados, analizados desde la perspectiva de los documentos conservados en la actualidad en la Sección "Guerra Civil» del Archivo Histórico Nacional, fueran muy distintos en cuanto a la recuperación de documentación masónica y en cuanto a la sección político-social. En efecto, aunque el ámbito de actuación del servicio abarcaba tanto a la «zona ocupada como a la zona a ocupar", se recogió exhaustiva, y podemos decir que casi íntegramente, la documentación masónica. Por el contrario, salvo alguna muestra excepcional, la documentación político-social recuperada procede exclusivamente de las zonas ocupadas a partir de la toma de Bilbao; es decir, desde el momento de la puesta en marcha del servicio de recuperación. La razón principal explicativa de este hecho no es una y simple, sino más bien una combinación de elementos. En primer lugar, la extensión y el volumen de las sociedades masónicas no era comparable, en modo alguno a la de las entidades politicas, sindicales, militares o administrativas de la República. En segundo lugar, las nuevas autoridades locales y los jefes militares de las diversas unidades tenían muy claro el que los enemigos principales por capacidad organizativa y de actuación eran, además de las instituciones republicanas, sobre todo, los partidos y los sindicatos obreros, haciendo de los domicilios de estos lugar de intervención. Tales domicilios, además de estar claramente localizados sin excesiva investigación, ofrecían un buen botín de todo tipo, no sólo y principalmente documental. Marcelino de Ulibarri y Eguilaz, en escrito de fecha 24 de enero de 1938 , sin destinatario, pero probablemente dirigido a Serrano Suñer anotaba que

“... que estas operaciones de registro se efectúan en plazas recién conquistadas, en las que el pillaje -que ahora han dado en llamar requisa- está a la orden del día, ya que las autoridades no pueden ejercer en los primeros momentos la debida vigilancia, y también por el falso concepto de que no es robar apropiarse de cuanto existe en un domicilio de un rojo... ${ }^{12}$.

12 "Servicio de Recuperación de Documentos" (24 de enero de 1938). En AHN, SGC: DSD/Sec. Expedientes de asuntos y correspondencia, leg. 23. 
En tercer lugar, es incuestionable que hubo un mayor celo en la exhaustividad para con la incautación de los documentos masónicos.

El mayor de los conflictos de competencias quedaba claramente planteado con la Auditoría del Ejército de Ocupación. Al situarse en la órbita de la jurisdicción castrense la inmensa mayoría de las personas no ya sólo con responsabilidades, como es sabido, sino simplemente con participación mínimamente destacada en el Ejército de la República y, principalmente en las organizaciones integrantes del Frente Popular, la utilización de los documentos como pruebas de convicción, pero sobre todo la localización de tales individuos a partir de los documentos, será un objetivo prioritario de los consejos de guerra. En esa tarea la Auditoría del Ejército de Ocupación será la institución fundamental. No habría otro camino que la labor conjunta de ambos organismos, Auditoría y Recuperación. Así, en primera instancia se sitúa en el seno de la oficina central de Recuperación de Documentos en Salamanca, una dependencia delegada de la Auditoría del Ejército de Ocupación y las delegaciones que "ad hoc" constituyó Recuperación de Documentos en localidades conquistadas, como en el caso de Barcelona, se instalaron en los propios locales de la Auditoría. La colaboración fue muy estrecha y eficaz. En el ya citado informe de 4 de agosto de 1937, Ulibarri y Eguilaz señalaba que

«... a la Auditoria del Ejército de Ocupación presta el servicio (de Recuperación de Documentos) una función útil, toda vez que pone a su disposición los documentos recuperados de personas que han de ser juzgadas, también y como quiera que la citada Auditoría prepara su sección de información con vistas a actuaciones futuras, es útil al servicio de recuperación ensanchando sus medios de adquisición de datos interesantes y a la recíproca el servicio de Recuperación puede tener en el servicio de información de la Auditoría una ayuda eficaz para indicación de personas cuyos domicilios puedan ser registrados con probabilidades de hallar en ellos cosas interesantes...".

Tal fue en efecto el resultado final. Si entre 1937 y 1940 Recuperación de Documentos sirvió información a la Auditoría del Ejército de Ocupación $y$, en general, a las múltiples instaricias de la justicia militar que solicitaron datos, la Auditoría dejaría en Salamanca, en el servicio de Recuperación el fichero confeccionado por sus anteriormente mencionados servicios de información propios.

Pasados unos meses y conforme se fueron asentando tanto la oficina central de Recuperación como sus delegaciones territoriales se planteó la conveniencia de crear una sección de "Justicia", situando al frente de ella o de ellas (se creó también en las delegaciones) auditores del Cuerpo Jurídico Militar. Se decidió así organizar, en primer lugar 
«... organizar dentro del servicio la parte del Archivo que exprese actividad personal delictiva o peligrosa..."

y en segundo término

«... coordinar nuestro servicio por medio de la Sección de Justicia con la máquina judicial del Estado, y también con la Policía, dando a esta palabra Policia un sentido amplio y haciendo extensivo también la coordinación a las esferas administrativas, de depuración etc..." ${ }^{13}$.

A pesar de que las relaciones con el principal competidor en potencia, la Auditoría, se habian resuelto en la práctica satisfactoriamente para los intereses del servicio de recuperación, fue constante, a lo largo de 1937 y los primeros meses del 38 , la solicitud de un decreto que regulara taxativamente el tema de la exclusividad en la función. Los componentes de los equipos de recuperación necesitaban un soporte legal para enfrentarse a los numerosos obstruccionistas de todo tipo. El primer mecanismo de soporte a los trabajos de recuperación, una circular de Franco a los Generales en Jefe, se mostraba claramente insuficiente:

«... En relación con el primer requisito, el que tituló Exclusividad de actuación, urge la aclaración de S.E. a los Generales en Jefe y quizá fuera mejor y más práctico que se dictase una Orden o un Decreto, la importancia y la conveniencia de pública divulgación lo requiere..., debía en ella contenerse una cláusula penal para los contraventores u obstruccionistas..." ${ }^{14}$.

Atendiendo a las peticiones de Ulibarri, tras la constitución del primer gobierno formal de la España Nacional, Serrano Suñer, ministro del Interior, a quien en su privilegiado lugar político en Salamanca, ya habia hecho partícipe el navarro, de todas estas preocupaciones, siempre bien recibidas por el cuñado de Franco ${ }^{15}$, da un decreto, el 26 de abril de 1938 regulando el servicio de Recuperación ${ }^{16}$. El mencionado decreto, recoge en esencia, en su preámbulo, la necesidad de

13 "Lineas generales sobre organización de la Sección de Justicia en la Delegación del Estado para la Recuperación de Documentos o en el organismo que en adelante si instituya para continuar sus fines". (Documento sin fecha y sin firma [1939]). En: AHN, SGC: DSD/Sec. Exptes. de asuntos y correspondencia, leg. 23.

14 Informe de M. de Ulibarri a Franco (4 de agosto de 1937), citado en notas anteriores.

15 Desde su llegada a Salamanca, Ramón Serrano Suñer va a mantener un gran interés por todo lo relacionado con la "Recuperación de Documentos". Incluso podemos aventurar que en la labor de unificación de Fatange con los carlistas, jugaría un papel trascendental la relación con Marcelino de Ulibarri y la colocación de éste al frente, primero de la Delegación de Asuntos Especiales y, más tarde, de la OIPA y, por último, de la Delegación del Estado para la Recuperación de Documentos.

${ }_{16}$ Publicado en el "B.O.E." n553, del día 27 de abril de 1938, pág. 6.986. 
“... unificar e intensificar, tanto en la retaguardia como en las zonas que se vayan ocupando, la recogida, custodia y clasificación de todos aquellos documentos aptos para obtener antecedentes sobre las actuaciones de los enemigos del Estado..."

pero modifica sustancialmente los dos primeros textos propuestos por Ulibarri ${ }^{17}$. En primer lugar, aunque se menciona, como hemos visto la necesidad de unificar la tarea de recuperación reconociéndose que «... ha venido haciéndose de un modo fragmentario...", no se recoge, finalmente la expresión acuñada de "exclusividad de actuación», y mucho menos, la cláusula penal propuesta de que

«... los contraventores serán considerados como autores de un delito de auxilio a la rebelión...».

Tampoco se hace depender a la naciente Delegación del Estado para la Recuperación de Documentos de la Secretaría General del Cuartel General del Generalísimo sino del Ministerio del Interior. Por último, y lo que va a tener mayor trascendencia, en su artículo $3^{\circ}$, el decreto subordina la actuación de la Delegación "... a las supremas autoridades militares en poblaciones recién liberadas..." indicando que

“... Los servicios de la Delegación quedarán coordinados con los demás servicios integrantes de las columnas y organismos de ocupación...".

Al darle forma final, por tanto, el servicio quedaba bajo la dependencia del Ministerio del Interior (de Gobernación, posteriormente, al integrarse ambos bajo la jefatura de Serrano Suñer, tras la muerte de Martínez Anido) mientras que la Delegación de Asuntos Especiales, quedaba en el ámbito de la dependencia de la Secretaria particular del Generalísimo (más tarde de la Presidencia del Gobierno). La Oficina de Investigación y Propaganda Anticomunista, como hemos visto se integra en la práctica, desde antes de producirse el decreto de 26 de abril, en Recuperación de Documentos; de ella no volveremos a encontrar la menor mención. A

\footnotetext{
17 Conocemos tres anteproyectos de decreto. El primero de fecha 4 de agosto de 1937, el segundo y el tercero sin fecha. En el último de estos tres borradores desaparecen ya las cláusulas penales y se deja en blanco la dependencia orgánica de la Delegación. Particularmente destacaremos que en el primero se incluye la propuesta de Delegado Nacional, en nota manuscrita a lápiz de D. Manuel Martin Sastre. En el tercero hay, en su artículo 3, un organigrama completo del servicio, figurando en él, ya integradas, una Sección Especial $1^{\text {a }}$ dedicada a Anticomunismo y una Sección Especial $2^{a}$ dedicada a Masoneria, además de las secciones: Recuperación, Archivo, Militar, Juridico-Militar, Investigación y Vigilancia. Propaganda y, por último, de Enlace con los organismos internacionales.
} 
partir de este momento el único campo común para con los documentos será el de la exclusiva recogida, siendo los masónicos puestos inmediatamente al servicio de la Delegación de Asuntos Especiales. El nombramiento de D. Marcelino de Ulibarri y Eguilaz como delegado del Estado para la Recuperación de Documentos, salvará este escollo al hacer coincidir la cabeza de ambos organismos en una sola persona. Aunque la unificación definitiva de ambas instituciones no se produciría hasta 1944, en la práctica vamos a encontrar referencias comunes a los archivos, hablándose, en el lenguaje corriente del personal afecto a los mismos, de una Sección Especial (documentación masónica al servicio de la Delegación de Asuntos Especiales) y de una Sección Político Social, para el resto de la documentación. Ambas, además, permanecieron, hasta la fecha señalada, ubicadas en edificios distintos en la capital salmantina, la primera, la Sección Especial en el Seminario, en la Clerecía, y la segunda, la Sección Político social, en el Noviciado de Jesuitas.

No deja de sorprender el hecho de que en plena guerra, la creación de un organismo del tipo del que venimos analizando se publique en el Boletín Oficial del Estado, garantía clara de que acabaría conociéndose su existencia por el enemigo, y que éste procuraria, ante la inminencia de nuevas pérdidas territoriales, hacer desaparecer los posibles vestigios de sus actuaciones. Hemos de suponer que sólo hay una razón lógica para justificar el hecho: importantes presiones sobre Serrano y sobre el propio Franco para que se publicara, asi como la puesta en balance de los posibles beneficios de dotar al servicio de Recuperación de un instrumento de actuación de la máxima garantia frente a terceros frente a los hipotéticos riesgos.

No tardaría en efecto, en aflorar una seria preocupación por la seguridad de los archivos. El día 13 de diciembre de 1938, Ulibarri escribe a Franco y a Serrano ante la lectura en el "Boletín de información Roja», no 4 (7-12-38) de la siguiente noticia:

"EL FAMOSO FICHERO DE FRANCO. DOS MILLONES DE CONDENADOS A MUERTE. RADIO TORRENTE a las 8,15. Barcelona. En la reciente operación del Ejército republicano en el Segre, se ha hecho prisionero un estudiante cura que dijo había pertenecido a las Brigadas de Recuperación de documentos que hay en todas las unidades de combatientes del ejército faccioso. Declaró que la idea de formar un gigantesco fichero clasificado de los españoles liberales fue de un profesor de Latín sujeto conocido en la época de Martínez Anido en Barcelona... Las Brigadas de recuperación entraban en los pueblos inmediatamente después que las hordas armadas recorriendo los edificios públicos, locales de partidos y domicilios particulares recogiendo documentos, cartas, recibos, etc. que en cajas lacradas enviaban a Salamanca. Por este procedimiento han conseguido los rebeldes montar el fichero de dos millones de sentenciados a penas de muerte". 
En concreto a Ramón Serrano Suñer le dice:

\begin{abstract}
"Desde que vi... que los rojos tienen localizados estos Archivos, no estoy tranquilo ante el temor de un golpe de mano que criminalmente pudiera ocasionar con un incendio la irreparable pérdida de este tesoro de antecedentes que encierra...” ${ }^{18}$.
\end{abstract}

El Delegado de Recuperación de Documentos plantea toda una serie de medidas preventivas a tomar, fundamentalmente la del traslado de la Sección Político Social desde el Noviciado de Jesuitas a un lugar seguro. No le preocupa la Sección Especial, o masónica, que se considera en excelentes condiciones de seguridad y vigilancia en la Clerecía. Por el contrario, al concurrir en el Noviciado de Jesuitas el servicio de Recuperación de Documentos con un hospital militar y con instituto de enseñanza se hace muy difícil el control del acceso. Para independizarlo de cualquier otra actividad pública o privada Ulibarri ofrece la alternativa de un edificio en la plaza de los Bandos ocupado por el "Comando Truppe Volontaire», italiano. No sabemos si por razón de no incomodar a los aliados italianos o por considerar exagerados los temores del delegado, pero lo cierto es que su demanda no obtuvo respuesta satisfactoria.

\title{
c) La práctica de la recuperación
}

La labor de incautación se iría perfeccionando paulatinamente al amparo de las experiencias adquiridas. Pero ya en 1937 se dotó al servicio de un Reglamento Provisional. El mencionado reglamento se divide en dos capítulos. El primero dedicado a los "equipos de recuperación" y el segundo a las "oficinas de primera clasificación". La base operativa de los equipos de recuperación de éstos es que «serán móviles y se desplazarán allá donde las necesidades los requieran". Quizá en ello residió la capacidad de actuación del servicio, constituyendo pequeñas células cohesionadas y ágiles, que irian acumulando una experiencia práctica cada vez mayor. Un equipo de recuperación estaba compuesto por un jefe de equipo, dos auxiliares y un conductor, teniendo a su disposición un coche. El jefe de equipo, generalmente un oficial del ejército, tenia total autoridad sobre el resto de los componentes de su grupo y se situaba directamente a las órdenes del Jefe del Servicio, a quien daba cuenta diaria de su actuación y del que recibia,

18 Carta de M. de Ulibarri al Ministro del Interior, fechada en Salamanca el 13 de diciembre de 1938. En: AHN, SGC: DSD/Sec. Exptes. de asuntos y correspondencia, leg. 23. 
igualmente, las oportunas órdenes diarias para el servicio. Las "oficinas de primera clasificación constituian los núcleos locales del servicio, centralizando la labor de los equipos asignados a ellas. Su labor consistía en recoger y clasificar el material aportado por los equipos de recuperación para remitirlo, a la mayor brevedad posible a la oficina central en Salamanca. Contarían, estas oficinas de primera clasificación con un Jefe de Servicio, un equipo de clasificación y los equipos de recuperación que le fueran asignados. La oficina de primera clasificación tenía como misiones esenciales, las de registrar las entradas de documentación, clasificar someramente la misma, "teniendo en cuenta la procedencia y pensando en el organismo al que puedan ser más útiles: Auditoría, Policía, etc.», y preparar los legajos para su remisión a la oficina central.

A comienzos de 1938, el servicio de Recuperación de Documentos contaba con cinco equipos de recuperación y seis coches que si bien se consideraban suficientes para atender las necesidades entonces existentes en el frente de Aragón y en el frente de Madrid, se temía que ante una previsible caída vertical de uno de éstos, quedase completamente desbordado. Para tal contingencia se consideraba necesario crear un pequeño cuerpo de recuperación de documentos con, al menos treinta equipos disponibles ${ }^{19}$.

Tal y como se preveian los responsables del servicio, la caída de Barcelona y la caída de Madrid, posteriormente, así como, en menor medida las de Castellón, Valencia y Alicante, desbordaron a los equipos. El trabajo se acumuló, dilatándose los envios a Salamanca y haciéndose necesario, por otra parte, atender las perentorias demandas de información de los tribunales represivos. La variante introducida a partir de la toma de la capital catalana seria la de constituir no ya oficinas de primera clasificación sino delegaciones de Recuperación de Documentos que asumieron en su ámbito de actuación y en coordinación con la oficina central tanto las tareas de incautación como las de información. Por otra parte, en un informe firmado por Marcelino de Ulibarri, fechado en Salamanca el 17 de agosto de 1939, quedaba de manifiesto la imposibilidad que la oficina central tenia de ofertar información a los entes «depuradores»:

«... El delegado que suscribe, se considera en el deber de manifestar que este organismo se encuentra actualmente incapacitado para cumplir debidamente la misión que le está encomendada, quedando su actuación

19 "Recuperación de Documentos en la actualidad». En: AHN, SGC: DSD/Sec. Exptes. de asuntos y correspondencia, leg. 23. 
reducida a la ingrata tarea de expedir informes que en su mayor parte resul$\tan$ NEGATIVOS por tener sin clasificar más de 400 toneladas de documentación en la que seguramente se encuentran los datos que - de haber sido oportunamente entresacados- hubiesen permitido aportar datos positivos y pruebas documentales a la inmensa mayoría de los expedientes..., considerando urgente la contratación de 50 empleados que se ocupen de reanudar las tareas de clasificación de Documentos y confección de fichas, solicito la consignación del crédito que se juzgue preciso..." 20 .

Quizá por ello, se considerara más conveniente que los núcleos establecidos en las delegaciones locales, con un volumen más «controlable» de documentos atendieran de forma provisional el trabajo de proporcionar informes sobre antecedentes.

Ya en Barcelona, la envergadura del trabajo y la escasez de equipos de recuperación obligó a preparar muy minuciosamente, casi como si de una acción de combate se tratara, el plan de actuación, sectorializando la ciudad en cinco partes y asignando cada una de ellas a un equipo, dotando a los mismos de un plano con la localización de locales a registrar junto con la lista completa de las instituciones objetivo de cada uno de ellos. Paralelamente, ya en Barcelona se pone en marcha la práctica de levantar acta de cada uno de los registros así como de realizar un parte diario de novedades.

En cuanto a las prioridades en la actuación, se conservan unas normas, que acompañan al informe citado como "Recuperación de Documentos en la actualidad", que, bajo el título "Normas para efectuar los registros", hacen la siguiente clasificación de los locales susceptibles de registro en una población recién ocupada:

"1.- Locales oficiales del Gobierno Rojo, Ministerios, Consejerias, Ayuntamientos, Juzgados, Cárceles, Comités, Aduanas, elc. etc. Correos y Telégrafos; 2.- Locales de las Organizaciones Politicas, Partidos, Sindicatos, y demás lugares afines, Centros Culturales, Amigos de la URSS, etc. etc.; 3.- Locales ocupados por el Ejército Rojo, Estados Mayores, Oficinas de los distintos cuerpos, hospitales, etc. etc.; 4.- Locales ocupados por los rusos, Embajadas, Consulado, Estado Mayor, residencia particular, etc. etc. (Abastos por los suministros a los rusos); 5.- Cines (para las peliculas rojas) y casa de fotografia, (En éstas se encuentran fotos de pasaporte de los milicianos y afiliados, fotos de manifestaciones, desfiles, de personas asesinadas, etc. etc.; 6.- Librerías, Editoriales, Redacciones de

20 Borrador de un informe fechado en Salamanca el 17 de agosto de 1939 , en el que al pie figura la suscripción «El Delegado Nacional». En AHN, SGC: DSD/Sec. Expedientes de asuntos y correspondencia, leg. 23. 
Fuentes para el estudio de la represión franquista en el Archivo Histórico Nacional...

Periódicos, etc. etc.; 7.- Domicilios particulares de los jefes y dirigentes, etc.; 8.- Demás domicilios que por los informes que en la plaza se reciban, sean de interés registrar».

\section{EL FINAL DE LA GUERRA. NUEVAS ORIENTACIONES}

\section{a) El proyecto de Archivos Documentales de la Cruzada Española}

A los pocos meses de finalizada la contienda la labor de incautación o "recuperación» estaba prácticamente finalizada. Las cárceles se encontraban abundantísimas pobladas y la actuación de la jurisdicción castrense habia alcanzado a casi todos los que, sin posibilidad de salir al extranjero, o confiados en la benevolencia de las nuevas autoridades para "quienes no tuvieran las manos manchadas de sangre", habian jugado un papel activo en las jornadas de lucha. Algunos entendieron que el papel de los archivos salmantinos tenía que cambiar; al menos el nombre del organismo no podía seguir siendo el mismo. Por otra parte, el carácter de provisional que el decreto de 26 de abril de 1938 daba a la Delegación del Estado para la Recuperación de Documentos podia inducir a pensar en la simple y llana desaparición de los servicios y con ella, la integración de sus ficheros y documentos, como hubiera sido lógico, en la Dirección General de Seguridad, máxime cuando Recuperación de Documentos dependía del Ministerio de la Gobernación. En cualquier caso, la Delegación del Estado para la Recuperación de Documentos continuaria extiendo, sin cambio formales aparentes, hasta el mes de octubre de 1944.

Là opción del delegado, Marcelino de Ulibarri, fue clara: constituir una institución cultural para favorecer la difusión a la investigación de los horrores del comunismo y la masonería así como para engrandecer la labor de los sublevados. El 30 de mayo de 1939 Ulibarri escribe a Franco planteándole que

"... se impone una rápida transformación de todos aquellos organismos que, cual éste de Recuperación de Documentos, fueron creados durante la lucha con finalidades ulteriores de indole distinta. Precisa a tal fin: $1^{\circ}$. Modificar el nombre de éste organismo; $2^{\circ}$. - Designar lugar adecuado para su instalación definitiva; $3^{\circ}$.- Concretar el alcance de su misión... ${ }^{21}$.

21 «Recuperación de Documentos. Notas informativas sobre la transformación de dicho organismo". Informe dirigido por M. de Ulibarri a Franco con fecha de 30 de mayo de 1939. En: AHN, SGC: DSD/Sec. Exptes. de asuntos y correspondencia, leg. 23. 
Sobre la denominación del nuevo organismo, Ulibarri propone el título de «ARCHIVOS DOCUMENTALES DE LA CRUZADA DE ESPAÑA»y, en cuanto a la ubicación de los mismos, como no podia ser menos en este ambiente imperial, el Real Monasterio de San Lorenzo de El Escorial, en concreto en la planta baja de los edificios que forman el ala izquierda del llamado "Patio de los Reyes". Razones para la elección de tal ubicación se apuntan muchas y muy razonables, pero la que mejor hace comprender el alcance de la propuesta de Ulibarri y Eguilaz para con el futuro de Recuperación de Documentos es aquella lo cita como el lugar más adecuado y conveniente

«... por el ambiente evocador de paz, justicia, imperio y fe religiosa motivos de la fundación de aquel Santo Monasterio- tan en consonancia con los móviles de esta viril y Santa Cruzada Española».

Pero quizá el cambio más apreciable es el que se plantea en cuanto al alcance de la misión del organismo. Hay un profundo mesianismo en la propuesta, propio de alguien con una fe enorme en sus ideas, algo que chocaría claramente con el pragmatismo del franquismo. Afirmando que interesan al mundo entero las enseñanzas que se desprenden de la guerra española, se considera que

«... sería un error imperdonable circunscribir su misión (la del nuevo organismo) limitándola a meros efectos de carácter policiaco o de depuración nacional ${ }^{22}$. Debería más bien intensificarse el carácter histórico de sus estudios con tendencia a proporcionar a los estadistas y gobernantes, provechosas lecciones de política contemporánea...".

En el marco de tal empeño es en el que hemos de situar la idea obsesiva que a partir de tal momento no dejará de estar presente en los planes de Ulibarri y que, a pesar de no salirse con la suya en cuanto a este cambio de orientación historicista, acabará convirtiendo en realidad, aún sin la grandeza inicialmente ideada: el MUSEO MASONICO. Es aqui en donde podemos encontrar una explicación lógica al hecho de que en los locales que quedarían definitivamente ubicados estos servicios, en el antiguo Hospicio de San José, en Salamanca, se recreara una logia masónica, a partir de materiales originalmente incautados en las sedes masónicas, con una marcada intencionalidad contrapropagandística. Porque es muy difícil explicar tal inversión y con tal carácter si luego no pudo ser visitada sino por un reducidísimo grupo de privilegiados de las más altas esferas

22 El subrayado es mio. 
del régimen. Hasta la llegada de la democracia no sería pues una institución cultural, pero ello no impidió a Marcelino de Ulibarri poner en marcha su museo masónico. En su afán por mostrar las maldades de la Masonería, se apoyaba en que

"... la reserva con que la Masonería se ha desenvuelto en España y la indiferencia de la inmensa mayoría de los españoles respecto de dicha secta -nacida de su resistencia a dar crédito a tamañas aberraciones- ha originado, como reacción, una general curiosidad, ahora convertida en interés patriótico- por conocer cuanto se relaciona con dicha secta. Y para satisfacer esta general ansiedad... convendrá establecer, con carácter permanente uno o varios ${ }^{23}$ museos en los que pueda exponerse el abundantísimo material existente en esta Sección».

En su proyecto de Archivos Documentales de la Cruzada Española, Ulibarri va a contar con el apoyo de dos importantes padrinos. Por un lado con el subsecretario del Ministerio de la Gobernación, don José Lorente, y por otro, con Eduardo Comín Colomer, antiguo colaborador de don Marcelino en "Recuperación» y en 1939 en el Servicio Nacional de Seguridad del Ministerio de la Gobernación.

Comín aquilata el alcance del nuevo organismo no dejando perder del todo el componente represivo, y ofreciendo, como no podía dejar de ocurrir desde su responsabilidad en Gobernación una idea que sí sería aceptada, aunque más tardíamente en la organización del organismo: el "CERTIFICADO NACIONAL DE ANTECEDENTES". Ulibarri hace partícipe a Comín de sus proyectos tras escribir a Franco. Le pide opinión y le encarga la redacción de un proyecto completo de organización burocrática de la nueva institución. El proyecto asume en esencia esos ideales mesiánicos pero es mucho más pragmático, no dejando perder el principal valor para el régimen del organismo a reconducir; esto es, su capacidad de suministrar información. Así, en escrito de 10 de agosto de 1939 Eduardo Comín escribe al Delegado de Recuperación de Documentos adjuntándole dos textos; uno de ellos titulado “Bases y fundamentos para la creación del documento titulado "Certificado de Antecedentes", a expedir por el Archivo Documental de la Cruzada" y el otro "Archivo Documental de la Cruzada. Organización, funcionamiento, competencia y atribuciones de la Secretaría General” ${ }^{24}$. En el proyecto sobre el certificado de antecedentes Comín explica que

\footnotetext{
23 Se pensaba en al menos tres: cámara de aprendiz, cámara de compañero y cámara de

24 Todos ellos en: AHN, SGC: DSD/Sec. Exptes. de asuntos y correspondencia, leg. 23
} maestro. 
"La cantidad y calidad de la documentación recogida por la Delegación del Estado para la Recuperación de Documentos, impuisa a dar carácter activo a una importante rama del futuro Archivo Documental de la Cruzada, basado en la magnífica prueba constituida por los documentos originales de referencia, cuyo valor inestimable permite conocer exactamente, la verdadera personalidad de la casi totalidad de los españoles...".

Justifica a continuación que el único requisito en vigor para acceder a los empleos públicos en aquel momento es el "certificado de antecedentes penales", que considera absolutamente insuficiente, no sin razón, por cuanto

«... terminada la guerra, tal documento no tendrá en lo sucesivo la efectividad y eficacia anteriores... serán muchos lo que sin pruebas documentales en los Archivos del Ministerio de Justicia... habrán de ser admitidos a aquello por lo que opten..." .

No hemos localizado toda la correspondencia que debieron cruzar sobre el tema Ulibarri y Lorente, pero de la que conservamos se desprende que el proyecto fue acogido muy favorablemente, excepción hecha de la denominación, sobre la que el Subsecretario prefería la desaparición de los términos "archivos" y «cruzada» ${ }^{25}$.

El desarrollo de los acontecimientos, entre ellos el cese de José Lorente como Subsecretario de Gobernación, pero sobre todo la aparición en escena del Tribunal Especial para la Represión de la Masonería y el Comunismo, llevarían al aparcamiento provisional del proyecto.

\section{b) El Tribunal Especial para la Represión de la Masonería y el Comunismo}

El 1 de marzo de 1940 se promulgaba la Ley de Represión de la Masonería y el Comunismo. A la par, se creaba el Tribunal Especial para la Represión de la Masonería y el Comunismo, como entidad en el marco de una jurisdicción especial para juzgar los delitos tipificados en la mencionada ley. Con el texto legal se pretendía dar una alternativa sobre todo a la posibilidad de dar una cobertura a la represión de la Masoneria, por cuanto a los incluidos en el definido delito de comunismo, también nuevo, se les podía aplicar, en todos los casos la acusación de rebelión

25 Véase al respecto la carta remitida por M. de Ulibarri a J. Lorente el 19 de agosto de 1939. En: AHN, SGC: DSD/Sec. Exptes. de asuntos y correspondencia, leg. 23. 
militar, o, al menos la de auxilio a la rebelión, como de hecho sucedió. No ocurría lo mismo con los miembros de la orden, que no afiliados a los partidos o sindicatos obreros podían o no haberse integrado en las milicias republicanas.

También Salamanca tendría un triste protagonismo en el nacimiento de la figura del delito de masonería, del que podemos considerar padre al penalista Isaías Sánchez Tejerina, instructor de la causa contra la logia Helmántica en Salamanca, actuación pionera al respecto y autor de un interesante informe sobre el delito de masonería; informe que, por medio de Ulibarri, y a petición de éste elaboraría, en los primeros momentos de la actuación de la Delegación de Asuntos Especiales, para hacérselo llegar a Franco. En dicho informe, como era de suponer se contesta afirmativamente a la pregunta de si es delito la masonería, pero se plantean las dificultades para su tipificación:

“... En resumen: la masoneria es en España delito porque va contra los propios fundamentos de su misma existencia. Reconocemos que hay dificultades técnicas para hallar la tipicidad, que decimos los penalistas; esto es, para encajar en un articulo del Código Penal el hecho de ser masón, buscando la modalidad delictiva legal. Pero ante el Derecho penal extraordinario que ha hecho surgir la gran tragedia engendrada por la masonería, de acuerdo con el Frente Popular, Frente antifascista, Socorro Rojo, etc., es inútil andar a la búsqueda de la tipicidad. ¿Qué diría nuestro glorioso Onésimo Redondo y qué ley alegaría en su favor si se le hubiera preguntado en virtud de qué disposición legal repartia armas y reclutaba gente para la lucha? Es estúpido o perverso plantearse ciertos problemas de juridicidad en estos momentos. Así pues, y prescindiendo de otras actividades criminales comprobadas documentalmente, la masonería es delito en España, en un doble sentido; por si misma y por su actuación" 26.

El informe le debió parecer clarificador a Franco pues la legislación que se ponía en vigor se basaba sustancialmente en tales principios. Por otra parte, y lo que es de mayor trascendencia para nuestro estudio, por decreto de fecha 4 de junio de $1940^{27}$ se nombraba a los componentes del Tribunal, siendo éstos los siguientes: Presidente: D. Marcelino de Ulibarri y Eguilaz, Vocales letrados: D. Isaías Sánchez Tejerina y D. Antonio Luna García, Vocales: D. Juan Granell Pascual y D. Francisco Borbón y de la Torre, Duque de Sevilla.

26 «Dictamen sobre la masoneria. ¿Es delito la masoneria? Unidad de jurisdicción, de procedimiento y de sanción». En: AHN, SGC: DSD/Sec. Exptes. de asuntos y correspondencia, leg. 5, expte. 97 .

27 “B.O.E." $n^{\circ} 158(1940)$. 
Nuevamente volvía a situarse a la cabeza de un organismo relacionado con los temas masónicos a Marcelino de Ulibarri, lo que pretendía garantizar una perfecta armonía entre la Delegación de Asuntos Especiales, Recuperación de Documentos y Tribunal Especial para la Represión de la Masonería y el Comunismo.

De este modo podemos entender que, hasta la instalación definitiva del Tribunal se constituyese en Salamanca, en la "Sección de Servicios Especiales", el 17 de junio de 1940 una oficina provisional del Tribunal, a la que se remitirian la correspondencia y documentación relativa al recién creado Tribunal y en la que la coordinación de las tareas administrativas estaría encargada al Capitán de la Guardia Civil D. José Gómez Hernández, jefe de la Sección de Servicios Especiales ${ }^{28}$.

Por decreto de 31 de marzo de $1941^{29}$ se reorganizaba el Tribunal, cesando como presidente Ulibarri, y siendo sustituido por el Teniente General D. Andrés Saliquet y Zumeta, pasando el cesante a desempeñar la responsabilidad de vocal ponente. Al mismo tiempo, la Sección de Servicios Especiales quedaba afectada al servicio del Tribunal, asignándosele la misión concreta de

“... aportar a éste, los documentos, informes y certificaciones existentes en sus Archivos, así como cuantos datos e instrucciones aquel precise para su mejor actuación y desenvolvimiento, quedando de este modo convertida dicha "Sección Especial» en una oficina auxiliar a las órdenes y dependiente del ya citado Tribunal...» ${ }^{30}$.

Podemos volver a insistir en el interés masónico del Jefe del Estado, muy por encima de cualquier otro. Los dos primeros juzgados constituidos lo son para confeccionar sumarios por delitos de masonería y el mismo Ulibarri, como vocal ponente, en una nota al informe de actividades de la oficina auxiliar del Tribunal en Salamanca recogido en la citada memoria de 1941, se permite

«... solamente enunciar, para que ese Alto Tribunal medite sobre ellas, la necesidad de enjuiciar el "COMUNISMO" como comprendido en la ley...".

En efecto, hasta el día 19 de febrero de 1942 no se constituiría el juzgado $n^{\circ} 3$, con competencia limitada a la persecución del delito de comunismo.

\footnotetext{
28 "Memoria del Tribunal Especial para la Represión de la Masoneria y el Comunismo. Año 1941. En: AHN, SGC: TERMC/Memorias, libro $1 \%$

«B.O.E." no 91 (1941).

Memoria 1941...
} 
Aún así y como se desprende clarísimamente del informe de tal juzgado en la memoria del Tribunal de actividades de $1942{ }^{31}$, el hecho de haber sido casi todos los individuos sobre los que se han incoado expedientes por delito de comunismo, juzgados y condenados por la jurisdicción militar como auxiliares o adheridos a la rebelión militar llevó en la mayoría de los casos al sobreseimiento. Por otra parte, en los sumarios que tenían por fundamento los expedientes que remitía la Sección Político-Sosial de la Delegación del Estado para Recuperación de Documentos,

«... la falta de selección de los antecedentes remitidos, sin duda por ausencia del personal técnico necesario para hacerla, dio, lugar a incoar sumarios sobre base tan insuficiente que al llegarse al momento de su conclusión habian de elevarse, forzosamente, con propuesta de sobreseimiento provisional» 32 .

Asi, el Juzgado $\mathrm{n}^{\circ} 3$ acabaria instruyendo también sumarios por delito de masonería no sin plantear la posibilidad de reorientar la represión del comunismo haciendo entrar en la órbita del Tribunal las actuaciones tipificadas por la Ley de Seguridad del Estado de 29 de marzo de 1941, en cuanto a las actividades clandestinas producidas por el rebrote de la actividad comunista, clandestina en este caso, recogidas en el capítulo IV de dicha ley.

En definitiva, la creación el Tribunal para la Represión de la Masoneria y el Comunismo va exigir de los Servicios de Recuperación, que se ven claramente frenados en la práctica unificación de las Secciones Masónica y Político-Social, un renovado impulso de suministro de información, en este caso a nuevo y, quizá, inesperado usuario de tales servicios. Si hasta entonces los demandantes habían sido múltiples, con protagonismo destacado de la jurisdicción militar, a partir de 1940 y hasta 1963, el gran cliente va a ser el Tribunal Especial para la Represión de la Masonería y el Comunismo. La vocación mesiánico-historicista de Marcelino de Ulibarri queda definitivamente truncada en la práctica si bien él hace un nuevo intento de ponerla en marcha, volviendo a escribir al Subsecretario de la Gobernación, acompañándole el proyecto de Archivos Documentales de la Cruzada Española, el 4 de octubre de $1941^{33}$, una vez apartado de la presidencia del Tribunal.

\footnotetext{
31 Memoria del Tribunal Especial para la Represión de la Masoneria y el Comunismo. En: AHN, SGC: TERMC/Memorias, libro $2^{\circ}$.

32 Memoria $1942 .$.

33 Carta de M. Ulibarri al Subsecretario de la Gobernación, fechada en Salamanca el 4 de octubre de 1941. En: AHN, SGC: DSD/Sec. Exptes. de asuntos y correspondencia, leg. 23.
} 


\section{c) La Delegación Nacional de Servicios Documentales}

La solución definitiva a la provisionalidad con que se constituyó la Delegación el Estado para la Recuperación de Documentos, no podia venir ya de otra manera que a través de su integración global bajo la Presidencia del Gobierno, integradas de hecho como estaban en la dinámica del Tribunal de Represión de la Masonería y el Comunismo tanto la Delegación de Asuntos Especiales, por disposición legal, como la Delegación de Recuperación de Documentos, por la dinámica cotidiana.

Por decreto reservado $n^{0} 52$, firmado por Franco el 30 de septiembre de 1944 y comunicado por el Subsecretario, D. Luis Carrero Blanco, en fecha 4 de octubre de $1944{ }^{34}$, se creaba la Delegación Nacional de Servicios Documentales, dependiente de la Presidencia del Gobierno,

“... bajo la que se unifican las que hasta el presente se denominaban "Delegación del Estado para la Recuperación de Documentos" y "Delegación de Servicios Especiales"”.

Como función a desarrollar se establecen únicamente dos, en los artículos $2^{\circ}$ y $3^{\circ}$ del decreto:

«... proseguirá su labor de clasificación documental, y facilitará a cuantas dependencias oficiales lo soliciten en la forma y condiciones que se determinarán, los antecedentes de indole militar, política, social y secreta, que sobre personas físicas y jurídicas posea... La Dirección General de Seguridad, antes de entregar el Documento Nacional de Identidad a que se refiere el decreto de dos de marzo de mil novecientos cuarenta y cuatro, solicitará de la Delegación Nacional de Servicios Documentales cuantos antecedentes pudieran existir de cada uno de los titulares...".

Además de un servicio de información se convierte en un centro de control de la población, en la línea apuntada por Comín en su proyecto sobre el Certificado de Antecedentes, cometido que se asigna a la Delegación en exclusiva.

Hemos de resaltar el hecho de que este decreto sea reservado, si lo comparamos con la publicidad que en tiempo de guerra se dió a la creación de la Delegación del Estado para la Recuperación de Documentos, pero ese control directo y paralelo al de Gobernación sobre informaciones tan

34 Entre la documentación administrativa de la Delegación Nacional de Servicios Documentales pendiente de clasificación en el Archivo Histórico Nacional, Sección "Guerra Civil». 
amplias como las que podía aportar la Delegación, lo cierto es que Presidencia lo quiso mantener lo más en secreto posible.

Con el nacimiento de la nueva delegación, fue nombrado Delegado Nacional el coronel D. Francisco Javier Planas de Tovar, quedando Marcelino de Ulibarri únicamente en su función de vocal del Tribunal para la Represión de la Masonería y el Comunismo. Planas de Tovar, hombre próximo a Carrero Blanco en la Subsecretaría de Presidencia, se mantendría al frente de la delegación durante muchos años, hasta su fallecimiento, tras el que fue sustituido por el ayudante de Franco D. Jesús Fontán Lobé, almirante de la armada. Si bien con cambios de matiz en la gradación el servicio: Dirección General, Jefatura Nacional, etc., la estructura de la Delegación no cambiaría esencialmente ya hasta 1977, dividida a efectos funcionales en las dos secciones ya consolidadas por la práctica: Especial y Político-Social.

\section{LAS FUENTES DOCUMENTALES}

De nuestro estudio institucional obtenemos claramente una primera conclusión obvia: que hay dos bloques documentales en la Sección Guerra Civil del Archivo Histórico Nacional. No tanto el de la Sección Especial frente al de la Sección Político Social, división que es cierta, como uno de documentos acumulados a partir de las recogidas de Recuperación de Documentos frente a otro de documentos producidos por instituciones franquistas al servicio de la represión. Ambos están íntimamente ligados, pues el segundo no se puede explicar sin el primero, y forman un conjunto sin precedentes en los archivos de Europa occidental, como testimonio integral de una concepción del Estado, tan extraordinariamente particular como la del régimen de Franco. A pesar de ello, la Sección "Guerra Civil» del AHN, desde su constitución en 1979, ha despertado un lógico interés de los investigadores especializados en la historia del Movimiento Obrero, de la Guerra Civil, de la Masonería o de la España de la Segunda República, incluso de la España de la Restauración. Son ya, por otra parte, suficientemente conocidos los contenidos informativos sobre tales temas, localizados, obviamente entre el primero de los bloques de documentos que hemos definido con anterioridad. Al contrario, hasta fechas relativamente recientes, los estudiosos del fenómeno de la represión no han comenzado a valorar las posibilidades del archivo en esa línea de investigación. Hemos de reconocer que a ello hemos debido contribuir, de mayor o menor manera, los archiveros, potenciando las tareas de clasificación y descripción de los documentos del primer tipo, siendo ya relativamente 
abundantes los instrumentos de descripción existentes sobre los mismos así como las contribuciones sobre aspectos monográficos de estas fuentes.

Por tales razones, en esta ocasión nos vamos a ceñir, en exclusiva a comentar en un cuadro resumido las fuentes existentes del segundo tipo; es decir, los conjuntos documentales producidos directamente por las instituciones anteriormente analizadas que se conservan en el archivo.

\section{a) Fondos de Recuperación de Documentos}

Se conserva, en primer lugar, un conjunto de legajos (52) sin clasificar ni ordenar, pero que cuentan con un registro que describe someramente el contenido de tales unidades, procedentes de la oficina central de Recuperación de Documentos así como de las oficinas delegadas de Alicante, Barcelona, Bilbao, Castellón, Gijón, Madrid, Santander y Valencia. En este conjunto heterogéneo encontramos principalmente libros registro de incautaciones, actas de incautación, y partes diarios de servicio.

Fondo Delegación de Barcelona de Recuperación de Documentos, serie «certificaciones e informes sobre antecedentes»

Esta serie consta de 553 expedientes.

Fondo Delegación de Madrid de Recuperación de Documentos, serie "Certificaciones e informes sobre antecedentes"

Esta serie consta de 2.059 expedientes.

Fondo Delegación de Valencia de Recuperación de Documentos, serie "certificaciones e informes sobre antecedentes"

Esta serie consta de 6.200 expedientes.

b) Fondos de la Delegación de Servicios Documentales

Hemos de matizar que dentro de este fondo nos encontramos con documentación producida por la Delegación del Estado para la Recuperación 
de Documentos o por la Delegación Nacional de Asuntos Especiales, pero cuyas series, sin solución de continuidad se han conservado unidas a las de las secciones político-social y especial, respectivamente, a partir de la reorganización de 1944.

\section{Sección Político Social}

\section{- Fichero general}

El fichero general de la sección, confeccionado desde 1937, como hemos venido viendo en el estudio institucional, constituye un indiscutible y valiosísimo documento en si. A pesar de que la información suministrada por los más de dos millones de fichas que recoge no es homogénea y de que más podría considerarse un instrumento de acceso que una serie documental, nosotros sí le damos la consideración de tal, sobre todo, porque constituye, junto con el fichero general de la Sección Especial el nexo de unión entre los dos bloques de documentos definidos y por unión entre los dos bloques de documentos definidos y por tanto es la pieza angular de estructuración del conjunto de la actual sección "Guerra Civil», puesto que integra, igualmente todas las fichas de personas sobre las que se suministró información, tanto al Tribunal Especial para la Represión de la Masonería y el Comunismo como a otras instancias represivas, independientemente de que aquellos sobre los que se informa tengan o no antecedentes reducidos de los documentos incautados.

\section{- Secretaría General, serie certificaciones}

Esta serie consta de 92.469 expedientes de certificaciones expedidas a diversos organismos solicitantes, entre 1938 y 1977.

\section{- Secretaría General, serie expedientes de asuntos y correspondencia}

Recoge por destinatarios la correspondencia sostenida con diversos destinatarios entre 1937 y 1977, asi como un grupo de expedientes de asuntos, incluidos en la misma secuencia numeral del más variado espectro. Son treinta y cinco legajos.

\section{- Secretaría General, serie expedientes personales}

Contiene, en cuarenta legajos los expedientes personales de todas las personas que trabajaron en los servicios de recuperación y en Servicios Documentales entre 1937 y 1977. 


\section{- Documentación administrativa y contable}

En este apartado pretendemos dejar constancia de la existencia de 117 legajos sin clasificar ni ordenar que contienen la documentación contable del organismo asi como órdenes, nombramientos, disposiciones legales y otros materiales. A pesar de no estar organizado, este conjunto dispone de un registro que nos informa someramente del contenido informativo de cada una de las unidades.

\section{c) Sección Especial}

\section{Fichero general}

Podemos decir de él lo mismo que del existente en la Sección político social, salvo que es mucho más reducido en volumen y que se subdivide en varios ficheros especializados: masones (con un fichero especial por nombres simbólicos), rotarios, protestantes, evangélicos, teósofos y Liga de los Derechos del Hombre.

\section{Expedientes personales de masones}

La Sección Especial, precisamente por la independencia apuntada, confeccionó, a diferencia de la político-social, unos expedientes en los que fue situando cuantos documentos originales existieran sobre la persona en cuestión, procedentes de las incautaciones efectuadas en logias y obediencias. Estos expedientes se encuentran repartidos entre una denominada serie "A", en la que ocupan, aproximadamente los trescientos primeros legajos de los 825 de que se compone y una serie "B" exclusivamente compuesta de expedientes personales. En la serie "B", 833 legajos contienen este tipo de expedientes personales de masones, los numerados del 1 al 833 ambos inclusive, pero, además, y con numeración desde el legajo 1.001 al 1.504, encontramos legajos de expedientes de certificaciones negativas a solicitudes de organismos de la Administración.

\section{d) Fondo Tribunal Especial para la Represión de la Masoneria y el Comunismo}

\section{Serie expedientes de causas}

Esta serie la constituyen unos 65.000 expedientes, repartidos entre 1.203 legajos incluyéndose en ellos tanto causas vistas como sumarios 
archivados sobreseidos, tanto por delito de masonería como por delito de comunismo. Los expedientes abarcan una secuencia cronológica entre 1941 y 1962.

Libros de sentencias

Son 32 libros, con una secuencia cronológica entre 1941 y 1958, año de la última sentencia del Tribunal.

\section{Libros registro de causas}

Son seis libros en que se registran todas las causas abiertas por el Tribunal, desde la no 1 hasta la 64.386.

Libros registro de entrada y salida de correspondencia

Se conservan dos libros de entrada, de 1961 a 1971 y un libro de salida, de 1961 a 1971.

Diarios de sesiones

Son veinte libros en los que se anota el parte diario de actuaciones. Abarcan un período cronológico de 1941 a 1953.

\section{Memorias}

Dos libros (1941-1942).

Servicio de Ejecutorías

Dos legajos.

Comisión Liquidadora

Dos Legajos (1965). 
Correspondencia con el Ministerio de Justicia

Un legajo.

A todo ello, pero tratado independientemente, por su carácter especial $y$ al margen de la estructura general de los fondos integralmente unidos analizados hasta ahora, hemos de añadir, el FICHERO DE LA AUDITORIA DEL EJERCITO DE OCUPACIÓN, que de una forma burda y a partir de informaciones verbales fue geográficamente pueblo a pueblo, relacionando: $1^{\circ}$. - Con carácter general una somera ficha de la actuación de las fuerzas republicanas en el mismo (si hubo fusilamientos, colectivizaciones, peticiones de dinero a los desafectos...), $2^{\circ}$.- Las fichas personales de los considerados dirigentes izquierdistas. Lamentablemente no conservamos el fichero completo de todas las provincias. Ni siquiera sabemos si realizó de todas. 